\title{
Exploring Solitary Bone Plasmacytoma: A Rare Case Report
}

\author{
Pablo A. Brito-Souza, Gabriel M. Alexandre-Silva, Ana C. S. Oliveira, Kim Tavares Mesquita, Larissa Soares Cardoso, Manuela B. Pucca*
} Medical School, Federal University of Roraima, Boa Vista-RR, Brazil.

*Corresponding Author: Manuela B. Pucca Medical School, Federal University of Roraima, Boa Vista-RR, Brazil.

\section{Received Date: 16 August 2021 | Accepted Date: 05 November 2021 | Published Date: 26 November 2021}

Citation: P A. B-Souza, G M. A-Silva, A.C.S Oliveira, Kim T Mesquita, Larissa S Cardoso, Manuela B Pucca. (2021). Exploring Solitary Bone Plasmacytoma: A Rare Case Report. International Journal of Clinical Case Reports and Reviews. 9(2); DOI: 10.31579/2690-4861/164

Copyright: () 2021 Manuela B. Pucca, This is an open-access article distributed under the terms of the Creative Commons Attribution License, which permits unrestricted use, distribution, and reproduction in any medium, provided the original author and source are credited.

Abstract
The Solitary Bone Plasmacytoma (SBP) is a rare oncologic disease corresponding to less than 5\% of the malignant
neoplasms of the plasma cells. It is characterized as a localized aggressive tumor consequent to the accumulation
of monoclonal plasma cell neoplasms and, due to the rarity of the disease, there are only few clinical studies
reporting it especially regarding prognostic factors and treatment. Here, we report a fatal clinical case of SPB in
Roraima, the northernmost state of Brazil. The study shows a case of solitary bone plasmacytoma on the femur,
where the patient was submitted to the preconized radiotherapy cycles. However, over approximately four-years
following the diagnose, the patient required multi-modal approach to guarantee quality of life during the survival
time. Finally, this study explores SBP-related issues and examines the challenges physicians face when managing
the care of patients with SBP.
Keywords: mieloma; oncology; public health; cancer; radiotherapy; plasma cell; chemotherapy

\section{Abbreviations:}

SBP: FCECON: Center of Oncological Control Foundation; HGR: Roraima's General Hospital Rubens de Sousa Bento; HIF: Hypoxia inducible factors; Solitary bone plasmacytoma; ICU: Intensive care unit; IL-1: Interleukin 1; POEMS: peripheral neuropathy, organomegaly, endocrinopathy, and elevation of $\mathrm{M}$ protein and skin changes; SUS: Single Health System; VEGFs: Vascular endothelial growth factor; TNF$\alpha$ : Tumor necrosis factor $\alpha$

\section{Introduction}

Solitary bone plasmacytoma (SBP) is a rare oncologic disease, corresponding to less than $5 \%$ of plasma cells malignant tumors (Kilciksiz et al., 2012; Serin \& Hilmi Dogu, 2020). It is characterized as an aggressive localized tumor caused by the accumulation of neoplastic monoclonal plasma cells, found mostly in adults presenting about 55 years (Franck et al., 2021; Kilciksiz et al., 2012). However, in order to define SBP criteria, only a single bone area must be affected, without evidence of systemic disease (Say et al., 2014; Serin \& Hilmi Dogu, 2020). Nevertheless, the majority of patients presenting SBP progress to multiple myeloma within 3-5 years (Kumar et al., 2017; Matar et al., 2015; Pinto et al., 2012), requiring frequent and detailed investigation of patient calcium levels, anemia, and signs of renal insufficiency (- Sharma et al., [s.d.]; Kilciksiz et al., 2012).

In general, survival and progression of SBP are poorer than solitary extramedullary plasmacytoma. The main symptom of solitary bone plasmacytoma is bone pain with high risk of pathological fracture (Kumar et al., 2017; Matar et al., 2015) and the most affected bones include ribs, pelvis, humerus, femur, and bone marrow dense bones (e.g. spinal column vertebrae) (Grammatico et al., 2017; Kumar et al., 2017; Matar et al., 2015; Wang et al., 2020).

Due to the rarity of SBP disease, there are few studies about it and not a true consensus about the prognostic factors and treatment. This study reports a fatal clinical case of solitary bone plasmacytoma in Roraima, the Northernmost state of Brazil, and review the main aspects related to this rare disease.

\section{Case presentation}

A 73-year-old female from Boa Vista, Roraima (Amazon Region), Brazil, hypertensive and diabetic, referred pain on her right hip since August of 2014. After seeking assistance in orthopedics and neurosurgery specialties, without effective resolution, the patient was referred to a physiotherapy outpatient regimen. Nonetheless, the physiotherapy exercises increased the severity of pain to a level that opioids where needed to tolerate it and a deeply investigation was required.

The $\mathrm{x}$-rays of femurs revealed osteolytic lesions on the proximal third of the right femur (Fig. 1A) and the patient was referred to the geriatrician for oncologic investigation in Roraima's General Hospital Rubens de Sousa Bento (HGR).

To confirm the oncologic diagnosis, a femoral biopsy was performed on August $11^{\text {th }}, 2015$, revealing the presence of numerous plasma cells (Fig. 1B), a common evidence found in either multiple myeloma or plasmacytoma. However, immunocytochemistry evidenced that crystals were mainly positive for kappa (80\%) light chains. 
A tree-phase bone scintigraphy was also performed, evidencing increased blood flow in the upper third of the right femur, showing high bone remodeling, and local hyperemia, suggesting the diagnosis of a primary bone neoplasm (Fig. 2A). To complement the differential diagnosis, an angiotomography was required, showing diffuse atheromatosis (Fig. 2B).

Since the patient had no history of headache, vision problem, bladder or bowel complaints, hemoptysis, dysphagia, dyspnea; and no hepatosplenomegaly or lymphadenopathy, no other complementary tests was considered and the diagnosis of SBP was made.

Therefore, the patient was referred to the oncological service to perform 20 cycles of radiotherapy, which were performed from November $2^{\text {nd }}$ to $27^{\text {th }}, 2015$. Since Roraima state does not offer this service (i.e., Roraima is one of the three poorest state of Brazil), the patient was transferred to the nearest oncologic center in Manaus, $748 \mathrm{~km}$ far from Boa Vista, on the Amazonas' State Center of Oncological Control Foundation (FCECON).

After concluding the radiotherapy cycles, the patient returned to Boa Vista, Roraima. Unfortunately, the patients' persistent chronic pain did not decrease, being referred to the orthopedic specialty for the placement of an external fixation, as the external cortex of the femur was severely compromised.

The surgery was performed on March $6^{\text {th }}, 2017$, at Roraima's General Hospital Rubens de Sousa Bento (HGR), proceeding to drainage of paracortical purulent exudate (Fig. 3). Microbiological evaluation evidenced the presence of ampilicin and penicillin resistant Staphylococcus aureus. Thus, the patient initiated an antibiotic therapy composed of ceftriaxone and vancomycin and was kept in the intensive care unit (ICU) for 3 days followed by 3 days on hospital ward before discharging.

On April 1 1t, 2017 (20 days after the discharge), the patient regressed to the hospital presenting edema on right inferior limb, fever, and syncope. She was immediately taken to the emergency and promptly evaluated by the orthopedic specialist. The patient was diagnosed with osteomyelitis and was hospitalized to receive intravenous regimen of clindamycin and ciprofloxacin for 6 weeks, ending up to the resolution of the symptoms. The patient was discharged with a 6-months prescription of clindamycin. During the next 2-years, the patient kept a good clinical state and life quality, being frequently followed up by the hematology and the oncology services.

In May 2019 (58-months after the initial symptoms), the patient referred intense pain and paresthesia on her right foot (Fig. 5), with clinical aspects of a diabetic feet, including necrosis on the tips of the toes. Nevertheless, no specific medical intervention was performed since the patient evolved at home with dyspnea and loss of consciousness, requiring orotraqueal intubation on September $26^{\text {th }}, 2019$, at the main Roraima's hospital, HGR. Despite being stabilized, the patient evolved with acute lung edema and myocardial infarction. The patient was taken into the ICU; however, she passed away at 4 am on October $11^{\text {th }}, 2019$, due to septic shock.

The study was conducted in accordance with the Declaration of Helsinki, and the protocol was approved by the local Research Ethic Committee under protocol numbers CAAE 36773220.7.0000.5302. Written informed consent was obtained from the patient.
A

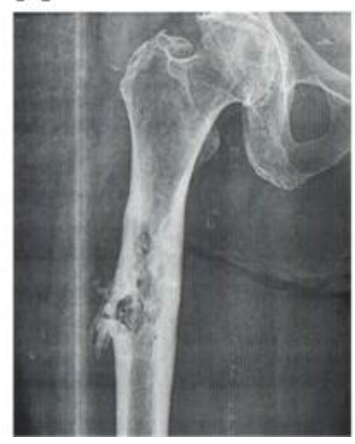

B

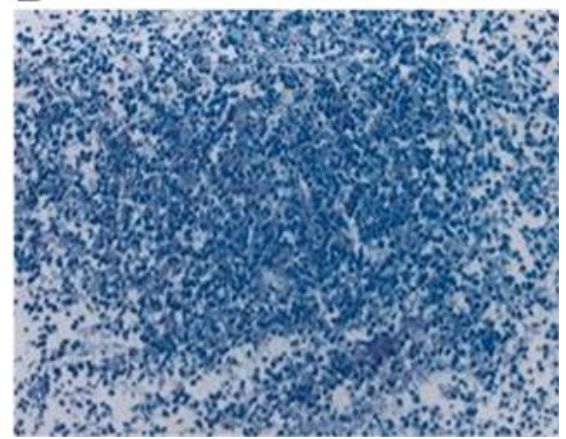

Figure 1. (A) Radiography evidencing osteolytic lesion on right femur. (B) Microscopic analysis of femoral biopsy evidencing plasma cell infiltration (colored with hematoxylin-eosin).

A

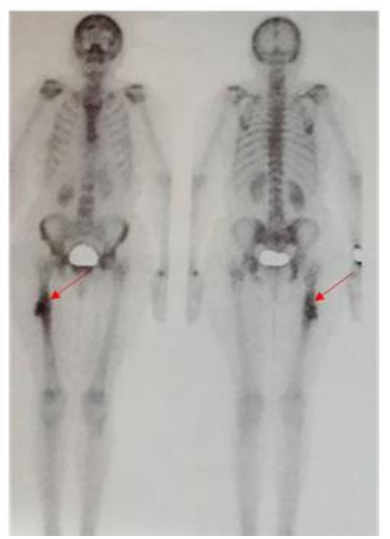

B

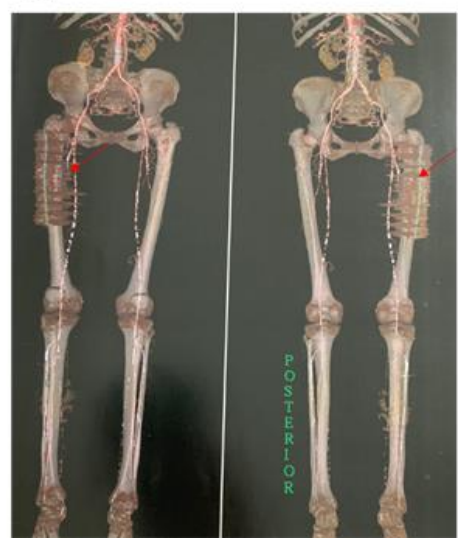

Figure 2. (A) Three-phase scintigraphy. The red arrows show the increasing of the radiopharmac capture on femoral lesion (August 2015). (B) Angiotomography. The red arrows show different points of atheromatosis leading to critical vessel stenosis (September 2019). 

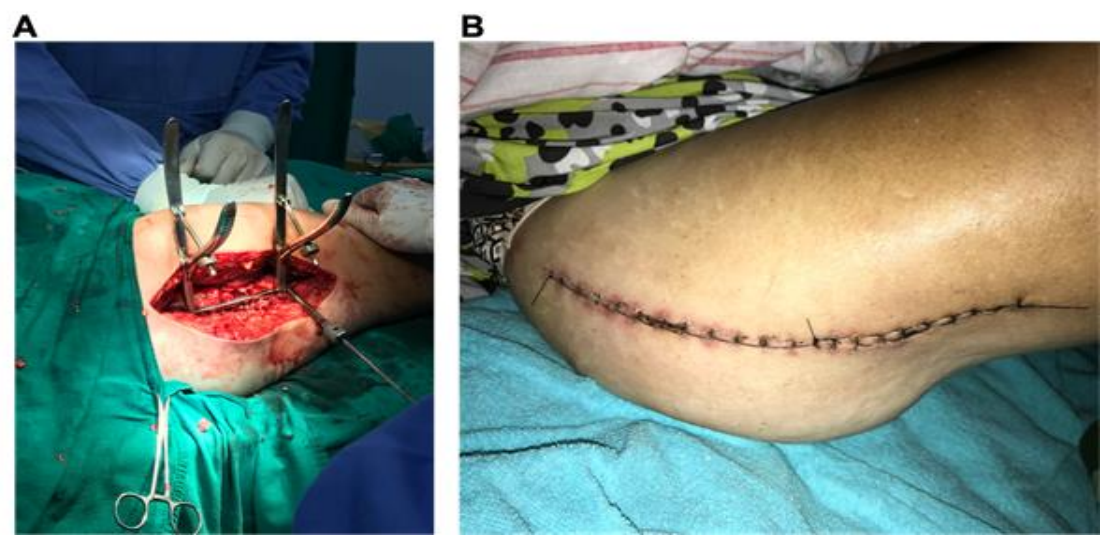

Figure 3. (A) Lateral aperture on femur, accessing the periosteum, after the drainage of the purulent exudate. (B) External aspect of the surgery after placement of the metallic fixation and suture.

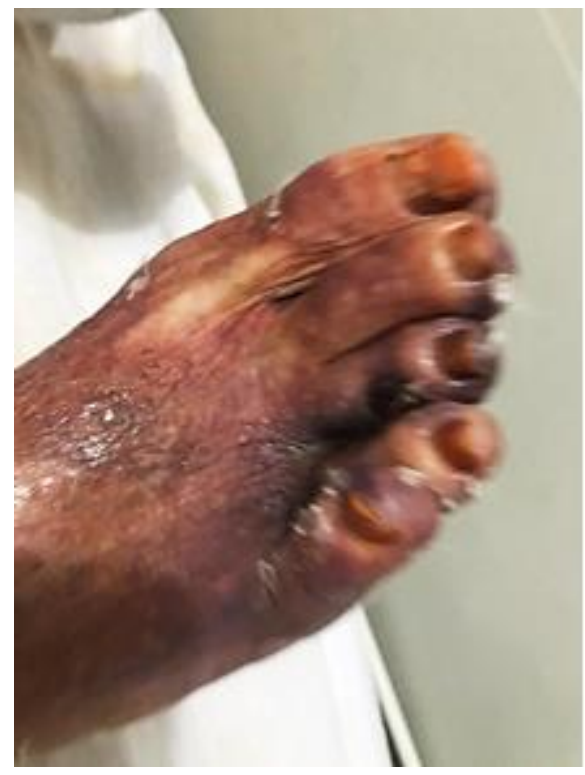

Figure 4. Necrosis of toes, right foot.

\section{Discussion}

Plasma cells are derived from activated B lymphocytes and are distributed through connective tissues, lymph nodes, spleen, and intestinal mucosa(Bayles \& Milcarek, 2014; Ribatti, 2017). Those cells are responsible for antibody production, presenting a pivotal role on humoral immune response (Nutt et al., 2015; Ribatti, 2017). The immunophenotype of these cells are the co-expression of CD138 and CD38. However, when malignant, plasma cells can also express different immunomarkers such as CD28, CD56, CD33 and CD117, and even can present the loss of others (e.g., CD27) (Ribatti, 2017). In addition, malfunctioned plasma cells can be detected by evaluating B-lymphocyte induced maturation protein-1 (Blimp-1). Also described as a "master regulator" of plasma cell differentiation and survival, Blimp-1 is important to the cell ability to secrete antibodies (Bayles \& Milcarek, 2014; Ribatti, 2017). For instance, the lack of Blimp-1, in mice, leads to dysfunctional plasma cell compartment (Ribatti, 2017).

Plasma cell neoplasms are characterized by the neoplastic proliferation of a single clone of plasma cells, typically producing monoclonal antibodies. Plasma cell neoplasms can present as a single lesion (solitary plasmacytoma) or as multiple lesions, usually with end-organ damage (multiple myeloma)(Faria, 2007; Merlini \& Palladini, 2012; Silva et al.,
2009). Solitary plasmacytomas most frequently occur in bones, although it can occur on soft tissue. As a matter of fact, the diagnosis of a solitary plasmacytoma requires the absence of target-organ lesion and a maximum infiltration of $10 \%$ on the bone marrow (Falcão et al., 2012; Grammatico et al., 2017; Pham \& Mahindra, 2019).

It is important to notice that solitary plasmacytoma corresponds to $1-10 \%$ of all plasma cells neoplasms, with few variations in accord to the population. Therefore this disease is relatively rare, which makes determining prognostic factors and treatment protocols a hard task (Bianchi \& Anderson, 2014; Dores et al., 2009; Kumar et al., 2017; Mendenhall et al., 2003; Riedel \& Pottern, 1992).

It is known that SBP has a higher risk of converting into multiple myeloma in comparison to extramedullary plasmacytoma (Holland et al., 1992; Riedel \& Pottern, 1992). Nevertheless, the entirety of the mechanisms involved in it (i.e. mainly by mutagenesis) remain unclear (Bianchi \& Anderson, 2014; Bolli et al., 2020; Firsova et al., 2020; Schürch et al., 2020). On the other hand, some factors have been associated with the progression of plasmacytoma to multiple myeloma, such as the expression of hypoxia inducible factors (HIFs), vascular endothelial growth factor (VEGFs), micro-vessel density, higher rates of CD166, downregulation of CD56, expression of SDF-1 $\alpha$ and CXCR4, 
encouraging the need of a systemic chemotherapy to treat plasmacytoma despite local radiotherapy (de Waal et al., 2016; Firsova et al., 2020). In fact, some authors suggest that the multiple myeloma occurs as a natural evolution of solitary bone plasmacytoma, which cannot be reverted, but merely delayed by radiotherapy, chemotherapy, or surgery (Bertanha et al., 2006; Fassas \& Tricot, 2001; Holland et al., 1992; Pinto et al., 2012).

Even though, the cornerstone of the treatment of SBP is radiotherapy, knowing to achieve local control in more than $80 \%$ of patients (Serin \& Hilmi Dogu, 2020; Wang et al., 2020). Surgical intervention is recommended for structural instability, whereas chemotherapy is reserved for those who do not respond to radiotherapy (Krause et al., 2011; Wang et al., 2020).

Approaches through surgery are usually recommended; however, the decision should consider the dual therapy of radiotherapy and chemotherapy first, as the surgery does not impact long-term local control, even when applied radiotherapy and chemotherapy afterwards. Although isolated chemotherapy does not present benefits to the patient, it is strongly recommended in cases where the radiotherapy has a high risk to fail, usually on lesions greater than $4-5 \mathrm{~cm}$. After treatment, a minimum follow-up of three years is recommended due to the risk of development of multiple myeloma (Bertanha et al., 2006; Lombardo et al., 2018; Pham \& Mahindra, 2019).

Regarding the patient presented on this case, she was submitted to radiotherapy without chemotherapy as adjuvant, and presented an incomplete resolution of chronic bone pain, associated to bone degeneration and pathological fractures. Nonetheless, the patient had multiple comorbidities, with long periods of hospitalization under antibiotic regimen.

The state of Roraima is one of the few on Brazillian Federation, along with Amapá, that does not possess a service on radiotherapy, thus, on such cases, the patient demands an out-of-home treatment, which is a tool offered through the Single Health System (Sistema Unico de Saúde, SUS) for patients whose medical treatment in unavailable on their district. There is great difficulty in reallocating those patients to other states, as the process of transference is extremely bureaucratic and the patients are left expecting vacancy on hospitals tied to the program (Barbosa et al., 2010; Folha Web, 2020; Santos \& Rodrigues, 2014). This prolonged await, associated to a lack of predictability, most of the times requires that the patient moves out from their homes to the city that offers the treatment, that is, when the patient does not give up or die prior to the opportunity of treatment (Barbosa et al., 2010). Indeed, free radiotherapy service offered by the Brazilian SUS is often full within a long waiting queue before beginning proper treatment.

A study done by the Brazilian Society of Radiotherapy shows that the average distance that a patient needs to travel to perform the radiotherapy is of $76 \mathrm{~km}$. Nonetheless, the access inequality covers a broad range, from $33 \mathrm{~km}$ in São Paulo (the most populous state) to $1605.5 \mathrm{~km}$ in Roraima (the least populous state), highlighting the hardships present to those who live on the northernmost part of the country. The project aiming to implement the radiotherapy in Roraima state, under the responsibility of the Health Ministry, began in 2018 and has not advanced so far.

Furthermore, it is known that the proliferation of plasma cells resulting on monoclonal gammopathies may have a strong association with dermatological injuries, which may be explained by high levels of endothelial growth factor (Lipsker, 2017). Skin changes in this context may fit into POEMS syndrome, a rare systemic disease whose acronym characterizes its components: peripheral neuropathy, organomegaly, endocrinopathy, and elevation of M protein and skin changes (POEMS). Its pathophysiological basis is the increase of monoclonal plasma cells, although its origin is not completely elucidated (Li et al., 2019). Indeed, our patient had clinical evidence of diabetic foot, indicating an association between foot necrosis and neoplastic recurrence. However, the patient also presented type II diabetes, which certainly contributed to the clinical picture and the severity of the foot damage. Also, the dermatological injuries enabled a gateway for pathogenic microorganisms. A very common complication of cancer and diabetic patients is the development of systemic infection or sepsis once they are known to present immunosuppression (Cecconi et al., 2018). Sepsis is known to activate the inflammatory response towards the releasing of pro-inflammatory mediator such as cytokines, such as interleukin 1 (IL-1) and tumor necrosis factor $\alpha$ (TNF- $\alpha$ ). These immunomodulators usually cause endothelial damage and activate the clotting cascade, leading to the generation of microthrombi (Cecconi et al., 2018; Lv \& Wang, 2016). This scenario can cause myocardial dysfunction and acute pulmonary edema, resulting in main causes of sepsis mortality (Lv \& Wang, 2016; Walley, 2018). During the patient last hospitalization (from September $26^{\text {th }}$ to October $\left.11^{\text {th }}, 2019\right)$, she presented several peaks of fever and leukocytosis, including neutrophilia, confirming that she had a bacterial infection.

The overall survival of solitary bone plasmacytoma are poorer than solitary extramedullary plasmacytoma, ranging from 4,5 to 6,5 years, especially because its higher rate of evolution in multiple myeloma. Indeed, our patient died after 5-years of the first symptoms. Ghiassi-Nejad et al. (2019)(Ghiassi-Nejad et al., 2019) presented a medium survival of 89 months (about 7 years) for SBP, with survival rates higher in younger patients with higher incomes treated in academic centers. Thumallapally et al. (2017)(Thumallapally et al., 2017) observed a higher 5-year-survival rate in patients who did undergo neoadjuvant radiotherapy. In other study, Jackson et al. (2019) (Jackson et al., 2019) shown that the median survival for those diagnosed with SBP was approximately 10 years. Surely the differences of survival rates feature several factors, such as older age, tumor size $>5 \mathrm{~cm}$, bone location, serum protein level at diagnosis, and bone marrow infiltration (Mheidly et al., 2019).

Based on the above, it is extremely difficult to determine the physio-pathological aspects that culminated in our patient death. Actually, multiple factors were responsible for causing the victim's death: (1) the SBP; (2) the patient comorbidities (i.e. diabetes, hypertension); (3) sepsis; and (4) myocardial infarction. Nevertheless, our study strengthen the need to create a treatment and follow-up protocol of SBP patients (i.e., requiring radiotherapy) in Roraima to align to the local context.

\section{Acknowledgement}

We thank the physicians and nurses of Hospital Geral de Roraima (HGR), who have made the commitment to better quality care for the patient. We specially thanks Andréa Giordana dos Passos Araujo, Eder Rodrigo Figueira Ribeiro, Dalson Denis da Silva Feitosa, and Carlos Patrick Araujo da Silva that assisted and took care of the patient during all the patient illness period. This study is in memorian of Claudete de Souza Brito, the patient of the study and an incredible human being. As an example of strength and resilience, even in her worst days of pain, she did not give up and let herself down. We expect that her case report can reach and contribute to the scientific community.

\section{References}

1. Sharma S, Tyagi S, Kumar, V. Paramolar tubercle-Bolk cusp: A case report. National Journal of Maxillofacial Surgery. 6(1); 76.

2. Barbosa, H. H. M. de M., Santos, A. L. M. dos, Cruz, R. A. P., Borges, R. G. L., \& Rodrigues Neto, T. dos S. (2010). Perfil dos pacientes atendidos pelo programa Tratamento Fora de Domicílio no Município de Belém, Estado do Pará, Brasil. Revista Pan-Amazônica de Saúde. 43-47. 
3. Bayles I, Milcarek C. (2014). Plasma cell formation, secretion, and persistence the short and the long of it. Critical Reviews in Immunology. 34(6), 481-499.

4. Bertanha F, Boufelli G, Camargo O P de, Baptista A M, Caiero M T, Oliveira C. R. G. de, Filippi R. (2006). Oncologic progression of bone plasmacytomas to multiple myeloma. Clinics, 61, 139-146.

5. Bianchi G, Anderson K C. (2014). Understanding biology to tackle the disease: Multiple myeloma from bench to bedside, and back. CA: A Cancer Journal for Clinicians. 64(6); 422-444.

6. Bolli N, Martinelli G, Cerchione C. (2020). The molecular pathogenesis of multiple myeloma. Hematology Reports. 12(3); 9054.

7. Cecconi M, Evans L, Levy M, Rhodes A. (2018). Sepsis and septic shock. The Lancet. 392(10141), 75-87.

8. De Waal, E. G. M., Leene, M., Veeger, N., Vos, H. J., Ong, F., Smit, W. G. J. M., Hovenga, S., Hoogendoorn, M., Hogenes, M., Beijert, M., Diepstra, A., \& Vellenga, E. (2016). Progression of a solitary plasmacytoma to multiple myeloma. A population-based registry of the northern Netherlands. British Journal of Haematology. 175(4), 661-667.

9. Dores G. M, Landgren mO, McGlynn K. A, Curtis R. E, Linet M. S, Devesa, S. S. (2009). Plasmacytoma of bone, extramedullary plasmacytoma, and multiple myeloma Incidence and survival in the United States. 1992-2004. British Journal of Haematology. 144(1); 86-94.

10. Falcão G. S, Falcão M. L, \& Farias J. (2012). Plasmocitoma ósseo solitário de mandíbula com apresentação imaginológica incomum: Relato de caso clínico. Revista Portuguesa de Estomatologia, Medicina Dentária e Cirurgia Maxilofacial, 53(1), 34-38.

11. Faria R O P, Rosa Malena D, Silva. (2007). Gamopatias monoclonais: Critérios diagnósticos e diagnósticos diferenciais. Revista Brasileira de Hematologia e Hemoterapia. 29; 17-22.

12. Fassas A, Tricot G. (2001). Results of high-dose treatment with autologous stem cell support in patients with multiple myeloma. Seminars in Hematology. 38(3); 231-242.

13. Firsova M. V, Mendeleeva L. P, Kovrigina A. M, Solovev M. V, Savchenko V. G. (2020). Plasmacytoma in patients with multiple myeloma Morphology and immunohistochemistry. BMC Cancer. 20(1); 346.

14. Folha Web. (2020, dezembro 15). RORAIMA CONTINUA SEM SERVIÇO DE RADIOTERAPIA. Folha de Boa Vista.

15. Franck L G, Bertrand K A J, Célestin B A, Ibrahim T, Ibrahiman T, Constance B, \& Cinthia N K. (2021). Plasmacytoma of the iliac bone in a seven- year-old girl: A rare tumor with no to ignore. Journal of Pediatric Surgery Case Reports. 64, 101582.

16. Ghiassi-Nejad Z, Ru M, Moshier E, Chang S, Jagannath S, \& Dharmarajan K. (2019). Overall Survival Trends and Clinical Characteristics of Plasmacytoma in the United States: A National Cancer Database Analysis. Clinical Lymphoma, Myeloma and Leukemia. 19(5):310-319.

17. Grammatico S, Scalzulli E, \& Petrucci M T. (2017). Solitary Plasmacytoma. Mediterranean Journal of Hematology and Infectious Diseases. 9(1):e2017052-e2017052.

18. Holland J, Trenkner D A, Wasserman T H, \& Fineberg B. (1992). Plasmacytoma. Treatment results and conversion to myeloma. Cancer. 69(6):1513-1517.

19. Jackson S D, Wiering B A, Herrmann A A, Hinz M A, \& Hanson L R. (2019). Solitary bone plasmacytoma compression injury disguised as back pain: A case report. Spinal Cord Series and Cases. 5(1):16.
20. Kilciksiz S, Karakoyun-Celik O, Agaoglu F Y, \& Haydaroglu A. (2012). A review for solitary plasmacytoma of bone and extramedullary plasmacytoma. The Scientific World Journal. 895765.

21. Krause S, Hillengass J, Goldschmidt H, Debus J, \& Neuhof D. (2011). Radiotherapy of solitary plasmacytoma. Annals of Hematology. 90(9):1093-1097.

22. Kumar R, Kumar N, Mohindro S, \& Radotra B D. (2017). Solitary plasmacytoma of temporal bone: A rare case report. Asian Journal of Neurosurgery. 12(1): 95-97.

23. Li H, Huang Y, Li Y, Zheng B, Cui J, \& Liu M. (2019). Endocrine Manifestations in POEMS Syndrome: A case report and literature review. BMC Endocrine Disorders. 19(1): 33.

24. Lipsker D. (2017). Monoclonal gammopathy of cutaneous significance: Review of a relevant concept. Journal of the European Academy of Dermatology and Venereology: JEADV. 31(1): 45-52.

25. Lombardo E M, Maito F L D M, \& Heitz C. (2018). Solitary plasmacytoma of the jaws: Therapeutical considerations and prognosis based on a case reports systematic survey. Brazilian Journal of Otorhinolaryngology. 84:790-798.

26. Lv X, \& Wang H. (2016). Pathophysiology of sepsis-induced myocardial dysfunction. Military Medical Research. 3:30-30.

27. Matar H E, Mottram C, \& Gudena R. (2015). Proximal femur giant solitary plasmacytoma of bone: Lessons learnt. BMJ Case Reports.

28. Mendenhall W. M, Mendenhall C M, \& Mendenhall N P. (2003). Solitary plasmacytoma of bone and soft tissues. American Journal of Otolaryngology. 24(6): 395-399.

29. Merlini G, \& Palladini G. (2012). Differential diagnosis of monoclonal gammopathy of undetermined significance. Hematology. American Society of Hematology. Education Program. 595-603.

30. Mheidly K, Lamy De La Chapelle T, Hunault M, Benboubker L, Benchalal M, Moreau P, Baugier de Materre A, Decaux O, \& Laribi K. (2019). New insights in the treatment of patients with solitary bone plasmacytoma. Leukemia \& Lymphoma. 60(11): 2810-2813.

31. Nutt S L, Hodgkin P D, Tarlinton D M, \& Corcoran L M. (2015). The generation of antibody-secreting plasma cells. Nature Reviews Immunology. 15(3): 160-171.

32. Pham A, \& Mahindra A. (2019). Solitary Plasmacytoma: A Review of Diagnosis and Management. Current Hematologic Malignancy Reports. 14(2); 63-69.

33. Pinto J A, Sônego T B, Artico M S, Leal C de F A, \& Bellotto S. (2012). Plasmocitoma extramedular de laringe. Int. Arch. Otorhinolaryngol. 16(3): 410-413. SciELO Brasil.

34. Ribatti D. (2017). The discovery of plasma cells: An historical note. Immunology Letters. 188: 64-67.

35. Riedel D A, \& Pottern L M. (1992). The Epidemiology of Multiple Myeloma. Multiple Myeloma. 6(2): 225-247.

36. Santos D L, \& Rodrigues P H. de A. (2014). Política, atenção primária e acesso a serviços de Média e Alta Complexidade em pequenos municípios. Saúde debate. 38(103):744-755.

37. Say F, Gürler D, \& Bulbul M. (2014). Solitary plasmacytoma of the femur: A case report. 31:251-253.

38. Schürch C M, Rasche L, Frauenfeld L, Weinhold N, \& Fend F. (2020). A review on tumor heterogeneity and evolution in multiple myeloma: Pathological, radiological, molecular genetics, and clinical integration. Virchows Archiv. 476(3): 337-351.

39. Serin I, \& Hilmi Dogu M. (2020). An unexpected situation in isolated nasopharyngeal mass differential diagnosis: Solitary 
extramedullary plasmacytoma. Otolaryngology Case Reports. 17: 100246.

40. Silva R O P e, Brandão K M A, Pinto P V M, Faria R M D, Clementino N C D, Silva C M F, \& Lopes A F. (2009). Mieloma múltiplo: Características clínicas e laboratoriais ao diagnóstico e estudo prognóstico. Revista Brasileira de Hematologia e Hemoterapia. 31:63-68.

41. Thumallapally N, Meshref A, Mousa M, \& Terjanian T. (2017). Solitary plasmacytoma: Population-based analysis of survival trends and effect of various treatment modalities in the USA. BMC Cancer. 17(1): 13.

42. Walley K R. (2018). Sepsis-induced myocardial dysfunction. Current Opinion in Critical Care. 24(4).

43. Wang L, Ren N J, Cai H, Cheng H F, Zhang H L, Peng X B, \& He Z W. (2020). Solitary plasmacytoma of the occipital bone: A case report. The Journal of International Medical Research. 48(8): 300060520914817.
This work is licensed under Creative Commons Attribution 4.0 License

To Submit Your Article Click Here: Submit Manuscript

DOI: $10.31579 / 2690-4861 / 164$
Ready to submit your research? Choose Auctores and benefit from:

$>$ fast, convenient online submission

$>$ rigorous peer review by experienced research in your field

$>$ rapid publication on acceptance

$>$ authors retain copyrights

$>$ unique DOI for all articles

$>$ immediate, unrestricted online access

At Auctores, research is always in progress.

Learn more auctoresonline.org/journals/international-journal-of-clinicalcase-reports-and-reviews 